\title{
A Abordagem e a Clínica no Atendimento aos Moradores de Rua Portadores de Sofrimento Psíquico
}

The Approach and the therapy in the attendance of street people who present mental suffering

Maria Mercedes Merry Brito

Centro de Saúde Carlos Chagas
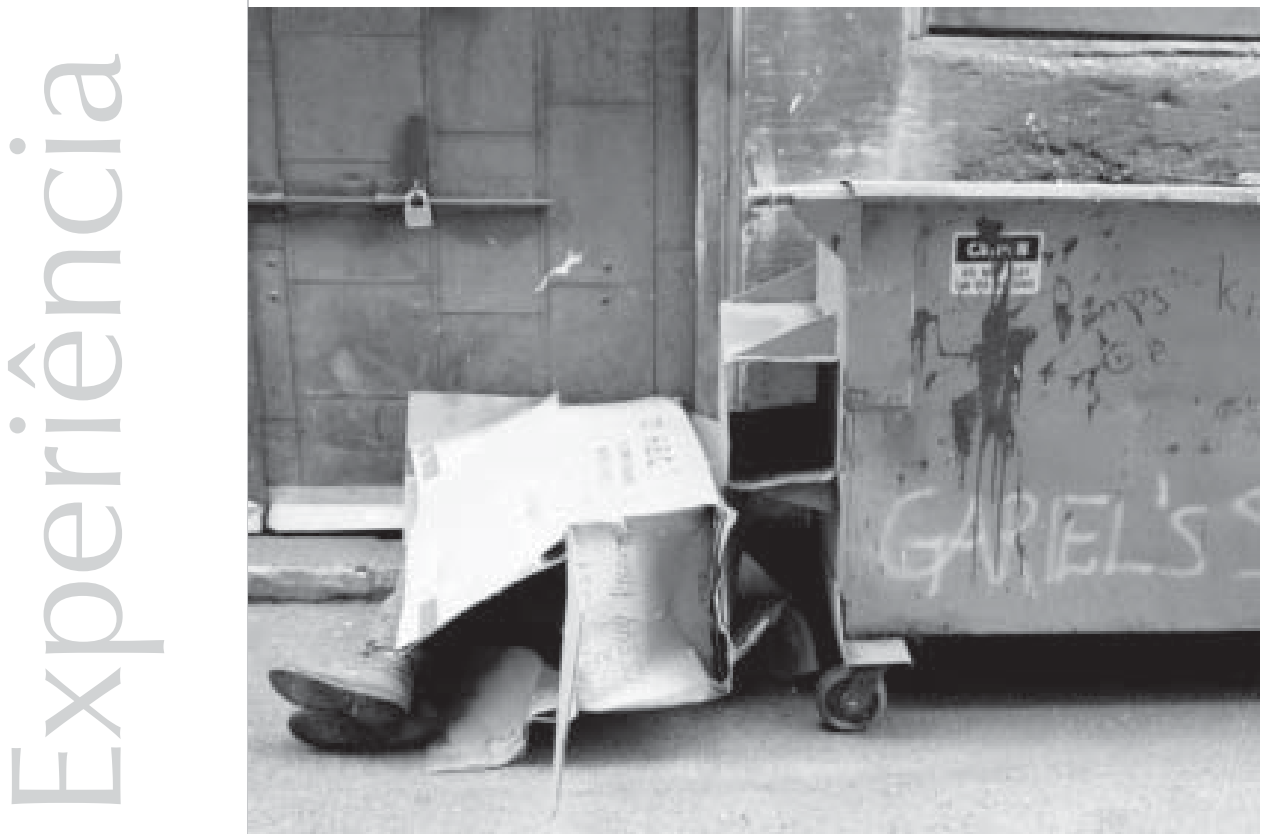
Resumo: A exposição da miséria nos espaços públicos, fruto do aumento das desigualdades sociais no mundo capitalista e globalizado, é um fenômeno urbano que se amplia nas grandes metrópoles brasileiras. As atividades desenvolvidas por grupos que vão buscar nas ruas das cidades modernas recursos para a sua sobrevivência tornaram-se uma demonstração exemplar de como a rua se transformou em espaço de construção de fronteiras econômicas, políticas e culturais. Pretendo fazer, neste artigo, um recorte nesse contingente que se amplia no espaço urbano, caracterizando um personagem, um antigo habitante das cidades, o portador de sofrimento psíquico, o denominado louco de rua. De forma singular, essa figura excêntrica e bizarra que faz parte da paisagem urbana, geralmente isolada do conjunto da população pauperizada que vive nas ruas, faz também, do espaço público, um lugar de moradia e sobrevivência. Um trabalho de abordagem, pesquisa e atendimento a essas pessoas que se encontram fora dos censos oficiais e das políticas públicas de assistência tem sido realizado desde 1996, por profissionais de saúde mental, em parceria com outros setores governamentais e ONGS, no Município de Belo Horizonte

Palavras-chave-espaços públicos, população pauperizada, loucos de rua

Abstract: The exposition of misery in the public spaces, which is a consequence of the social inequalities in the capitalist world, is an urban phenomenon that is increasing in the big Brazilian cities. The activities accomplished by the groups that get the resources for their survival in the streets of the modern cities became an exemplary demonstration on how the street has became a space of economic, political and cultural borders. I intend to focus, in this article, inside this human group that gets larger in the urban space, the street dweller, the so called street mad. In a singular way, this strange and eccentric figure, who is a part of the urban setting and has generally been isolated from the other street people, also makes a place dwelling and survival out of the urban space. This is a work of approaching, research and attendance to these people, who are out of the official census and the public policy of assistance that has been carried on since 1996 by mental health professionals, together with other government sectors and non-government organizations, in Belo Horizonte-MG.

Key words: public spaces, poor population, street mad.

\section{A população moradora de rua: quem são, de onde vêm?}

A exposição atual da miséria no tecido urbano das grandes metrópoles tem sido objeto de estudos muito recentes das ciências sociais e humanas e da Antropologia cultural. "É quando a cidade deixa de ser um conceito puramente geográfico para tornar-se um símbolo complexo e inesgotável da existência humana" (Calvino,1999). Os estudos sociológicos de fenômenos propriamente urbanos têm origem na denominada Escola de Chicago - 1915/ 1935 - caracterizada como "um modo de pensar de uma geração de estudiosos sociais norteamericanos"(Coulon,1995).Buscava-se nessa época, através da pesquisa empírica, a produção de conhecimentos que se constituíssem em ferramentas para a solução de problemas político-sociais concretos e essencialmente urbanos, tais como o problema do aumento da pobreza e a migração de um grande contingente populacional europeu na cidade de Chicago. O fenômeno urbano também se constitui em objeto de investigação de teóricos de orientação marxista, que se debruçam sobre o que poderíamos denominar de "Revolução Urbana", que diz respeito a um fenômeno complexo, que exige um tratamento teórico interdisciplinar e que advém de um processo no curso do qual explodem as antigas formas urbanas, a agrária e a industrial (Lefebvre, 1999).A cidade é vista como um campo de conflitos e tensões, como lugar de enfrentamentos e contradições que se produzem como resultado das continuidades
"Percebo, nesta ovenida", um inocente seguido pelas crianças ... admiro também esse pobre diabo. Vi esse pobre louco... que pretende fazer com tantos farrapos? Vi essas loucas rudes, cantando injúrias nas ruas..."'.

Michel Foucault 
"Da primeira vez que eu tive crise, me trouxeram para um hospital onde eu sofri muito com o veneno que me deram lá... depois, da outra vez, eu pedi para o motorista me deixar naquele parque...e assim foi". e descontinuidades dos processos de urbanização.

Os estudos dos fenômenos sociais que acometem as grandes cidades têm se avolumado na mesma medida do aumento da pauperização de um contingente crescente da população mundial, população essa que, por uma série de contingências que envolvem o fenômeno da globalização, dentre outros, é lançada na pobreza extrema, encontrando como único recurso de sobrevivência morar e/ou trabalhar na rua. A apropriação do espaço público por esses "noveaux pauvres" para o desenvolvimento de atividades de mendicância, mercantil, criativa ou moradia se fundamenta em um sistema de classificação que acaba por delimitar "arenas" cujas regras de convivência estão constantemente abertas ao debate entre eles e os concorrentes usuários desses espaços, que são os donos e trabalhadores de empresas, residentes e cidadãos que por aí transitam no cotidiano. A coexistência de usos, de interesses e atividades diversas no espaço público tornase possível através de negociações recorrentes, que objetivam a construção de acordos ou consentimentos forçados. A rua, longe de se constituir como um espaço do abandono, torna-se um espaço de organização de uma rede de camaradagem e convivência, conformando a integração hierarquizada de "uma fronteira em movimento"( Pessanha,1995), que prolifera nas grandes metrópoles, realizada por pessoas e grupos profundamente empobrecidos, lesados em sua integridade material e psíquica, em sua autonomia e sem os recursos básicos necessários à sua subsistência.

O debate sobre a apropriação do espaço público pela população pauperizada tem sido valorizado pelo poder público no Brasil nas duas últimas décadas, impondo ações muitas vezes dos próprios poderes locais, que vão desde a expulsão sumária, internamento em hospitais psiquiátricos, chacinas de índios e grupos inteiros, realizadas por desconhecidos e até mesmo pelas forças policiais. Uma senhora de 76 anos, moradora em um casebre feito de arame, ferro velho e tábuas de compensado, sob um viaduto de grande valor patrimonial em Belo Horizonte, nos diz: “Da primeira vez que eu tive crise, me trouxeram para um hospital onde eu sofri muito com o veneno que me deram lá... depois, da outra vez, eu pedi para o motorista me deixar naquele parque...e assim foi". Muito recentemente, um trabalho de pesquisa, abordagem, atendimento e reinserção social tem sido sustentado com a colaboração de algumas universidades, ongs e prefeituras mais progressistas do País. Entretanto, esse trabalho tem encontrado limites gigantescos na medida em que se confronta com questões de fundo que motivam esses deslocamentos - da casa para a rua -, que são: a ainda excessiva concentração de renda nas camadas sociais privilegiadas no Brasil, a ausência de uma política governamental de geração de trabalho e renda que considere as singularidades e as potencialidades dos sujeitos, a ausência de uma política digna de saúde, educação e habitação, o que dá às políticas públicas o caráter provisório e frágil das soluções compensatórias e assistencialistas. Na falta de uma política consistente, apresentam-se muitas vezes, nas ruas, os mais variados segmentos sociais caritativos, que acabam por realizar, com o desprendimento e boa vontade que lhes são próprios, a proeza de cuidar, mantendo as pessoas em um estado de indigência, humilhação e assujeitamento, alimentando um processo que poderíamos denominar institucionalização da população na rua.

\section{O lugar do louco no espaço da miséria}

Um recorte nesse contingente que tem se ampliado no espaço urbano desnuda e caracteriza um personagem, um antigo habitante das ruas das pequenas, médias e grandes cidades desde a antiguidade, o 
denominado "o louco de rua". De forma singular, essa figura excêntrica e bizarra compõe também o cenário das metrópoles modernas como personagem urbano, geralmente isolado do conjunto da população fixada nas ruas, fazendo também, do espaço público, um lugar de moradia e, a seu modo, algum tipo de laço, algum tipo de negociação e de aliança. São pessoas com sofrimento psíquico que podem ser agregadas a esse contingente da população de moradores de rua, numa condição de exclusão que foi sendo naturalizada através das épocas: os semideuses, no Tempo Mítico, os hereges endemoniados, na Idade Média, jogados nas galeras da purificação no Renascimento, como passageiros da "Nau dos Loucos", e recolhidos nos hospícios a partir da Idade Moderna.

São estranhos seres que, nos intervalos das internações psiquiátricas ou completamente resistentes a elas, habitam as praças, os terrenos baldios das cidades contemporâneas, as esquinas, as casas abandonadas. Caminhantes solitários das cercanias, às margens das estradas, às margens da cidadania, numa busca heróica e "marcovaldiana" de sobrevivência material e psíquica.

São pessoas, de modo geral, oriundas das camadas extremamente pauperizadas da população e, entretanto, diferentemente das demais, encontram, na estrutura psíquica que Ihes é própria - a psicose - um elemento agregador ao "estado de miserabilidade e desamparo em que se encontram" (dificuldade com o cuidado de si, alheamento com relação à questão do tempo, dificuldade maior e diferenciada de fazer laço social). Por conseguinte, terão dificuldades também no estabelecimento das mediações simbólicas necessárias na apropriação do espaço e no convívio com seus pares na miséria. Fazem laços com o mínimo de pessoas e são, geralmente, portadoras de uma dignidade avessa à filantropia, figuras de uma estética bizarra e singular, que vagam pelo território urbano ou se fixam em algum ponto do espaço público, carregados de objetos aparentemente inúteis, expostos às intempéries do tempo e às vicissitudes da rua, rua essa que tem se transformado "na instituição dos excluídos, criada pela sociedade brasileira, no "terreno baldio da cidadania"(Ferreira, 2001).

\section{O Projeto de Saúde Mental do Município de Belo Horizonte}

Uma rede de serviços substitutivos aos manicômios vem sendo construída pelo poder público municipal ao longo dos últimos doze anos em Belo Horizonte: os centros de referência para atendimento das situações de crise, os centros de convivência de artes e ofícios, as equipes de atendimento ambulatorial, recentemente agregadas às equipes de saúde da família, as residências terapêuticas para egressos de longa permanência hospitalar e os projetos de geração de renda e trabalho. Somando-se a esses dispositivos institucionais, instalou-se na cidade um debate político que envolve os mais diversos segmentos organizados da sociedade, o parlamento, as organizações não governamentais, particularmente o Fórum Mineiro de Saúde Mental, as instituições de formação de psicanalistas, a mídia, os órgãos jurídicos e de direitos, as universidades, os familiares e os próprios usuários dos serviços substitutivos aos hospícios.

É nesse contexto que as equipes ambulatoriais de saúde mental, que respondem pela organização da assistência preconizada pelo SUS/PBH - de universalização, regionalização e hierarquização da atenção à saúde em nível local - passam a atender a demanda da população de sua área de abrangência, incluindo já, há algum tempo, a população fixada nas ruas. As que se encontram fixadas na área central da cidade são, de maneira geral, oriundas das áreas mais empobrecidas,
São estranhos seres que, nos intervalos das internações psiquiátricas ou completamente resistentes a elas, habitam as praças, os terrenos baldios das cidades contemporâneas, as esquinas, as casas abandonadas. Caminhantes solitários das cercanias, às margens das estradas, às margens da cidadania, numa busca heróica e "marcovaldiana" de sobrevivência materiale psíquica. 
os grandes conglomerados e favelas, de Municípios que circundam a capital, de cidades do interior de Minas Gerais, de outros Estados e até mesmo de outros países. Esse trabalho de abordagem e atendimento de pessoas com sofrimento psíquico que fazem da rua um lugar de moradia constitui-se em um desafio no campo da saúde e da saúde mental, e tem sido realizado pelos profissionais de saúde mental com os órgãos de assistência social. É um trabalho que envolve, ainda, uma articulação com diversos atores sociais, tais como: o Ministério Público, os órgãos de controle urbano, de segurança pública, fóruns de direitos sociais, a Pastoral de Rua, associações de moradores, associações de geração de trabalho e renda, os empresários e lojistas e os níveis secundários de atenção à saúde e a rede hospitalar em geral.

\section{O Senhor dos Anéis - a construção e o estudo de um caso clínico/social}

"Onde o Nomedo-pai fora incluído não promove a significação fálica, aparece uma significação de suplência, colada em uma referência ideal tomada de empréstimo ao Outro materno"
A equipe de saúde mental da qual faço parte foi acionada em março de 1999, pela comunidade local, para efetuar a avaliação de um "estranho mendigo", fixado em um bairro nobre da cidade, que estava causando constrangimento aos lojistas e transeuntes da região. Deparamo-nos com um homem aparentando cerca de 30 anos, com uma apresentação estética impar. Trajava vestes sobre vestes, carregando sacos enormes repletos de argolas de todas as ordens e tamanhos, de couro, arame, barbante, fios de plástico, anéis em todos os dedos das mãos e contornando-lhe todo o corpo. Fez-nos pensar em um sujeito completamente desvestido de simbólico, que tecia, no oco daquela ausência, uma outra roupagem, um arranjo vital na estrutura da psicose. Inicialmente arredio à conversação, aos poucos, com o passar do tempo, foi se acostumando à minha presença e à dos demais técnicos escalados para aquela intervenção. Uma pesquisa junto aos moradores e trabalhadores da região trouxenos referenciais familiares e o tempo de fixação daquele senhor estranho naquele local. Várias visitas foram feitas à sua família, moradora em um bairro pobre da cidade e oriunda do norte de Minas Gerais.

Sua mãe, uma senhora viúva de 60 anos, já não fazia questão e nem acreditava no retorno desse "ingrato e improdutivo filho". Tinha mais dois filhos "trabalhadores", uma filha alcoólatra, outra de 20 anos, trabalhadora, e um irmão de 25 anos com história de internação psiquiátrica periódica. A saída do filho de casa havia se dado há cinco anos, após uma briga com um vizinho, resultando em seu encaminhamento para uma instituição psiquiátrica, de onde fugiu sem sequer ter sido atendido. Conta-nos ainda que o filho, desde a adolescência, cata e junta coisas da rua. "Parece que é coisa feita, não é doença, não". O marido, já falecido, a havia abandonado há muito tempo. Disse que ele não tinha gosto pelo trabalho, não punha as coisas dentro de casa, donde concluía que o filho havia puxado o pai.

A referência constante dessa mãe ao trabalho de alguma forma aparece no labor cotidiano desse homem que denominei de "O Senhor dos Anéis", isso porque, pelos relatos dos trabalhadores locais e da própria mãe, sua chegada na rua coincide com uma tentativa de trabalhar como engraxate. Não conseguindo manter-se nessa tarefa, passou a catar lixo e a envolver-se de anéis por todo o corpo, o que me fez pensar que ele, através desse labor exaustivo, tentava dar uma resposta ao desejo da mãe. "Onde o Nome-do-pai fora incluído não promove a significação fálica, aparece uma significação de suplência, colada em uma referência ideal tomada de empréstimo ao Outro materno" (Soler,1993). É ainda o que me parece ser, para esse sujeito, verdadeiramente, a realização de um trabalho na psicose, uma tentativa de curar as desordens do gozo, trabalho que demonstrava 
a existência de um arranjo vital na estrutura psíquica desse portador de sofrimento psíquico, como um significante importante que Ihe permite elidir, pelo menos por um certo tempo, o ser inútil e vazio que tem certeza de ser, promovendo, assim, uma realização assintomática do desejo.

Freud, no seu percurso de deciframento do caso Schereber, reconheceu, no delírio um trabalho psíquico, uma tentativa de cura, na qual o sujeito toma a seu cargo, solitariamente, os retornos do real do gozo. Em debate sobre o filme documentário "Dizem que sou Louco", sua produtora, a psicanalista Mirian Chnaiderman, apresenta-nos essa população fixada nas ruas da cidade de São Paulo, diferentemente dos sem teto, que, de alguma forma, enlouquecem tomados pelas drogas, pela violação de seus corpos, pelo desenraizamento identitário. Nessa ocasião, ela considerou a idéia de uma necessidade da estrutura psíquica em jogo. "Na rua, eles se aliviam de um barulho interno... quando as vozes ficam muito intensas..." Não sendo, portanto, o delírio, a única manifestação da eficácia do sujeito, havemos de nos perguntar se, no caso em questão, e em outros que estamos acompanhando nas ruas, não estaríamos diante de uma estabilização precária, indicando que os efeitos da foraclusão podem ser compensados com outros recursos que não a produção delirante indicada pelo argucioso espírito clínico de Freud.

Durante os dois anos que se seguiram ao nosso encontro com o "Senhor dos Anéis", ele muda algumas vezes de lugar de fixação e já responde, de soslaio, aos comprimentos da equipe de atenção. No contato com o entorno (moradores e trabalhadores da região), surge a referência de uma senhora, que the serve, todos os dias, o café da manhã. É ela que nos convoca, através de um telefonema, para nos informar que, por vários dias, ele não bate a sua porta, mantendo-se imóvel e embrulhado em alguns cobertores no seu lugar de fixação.
Numa visita de urgência, constatamos que ele apresentava um quadro de infecção aguda, causada por um dos anéis que trazia no dedo anular. Diante desse fato, convidei-o a ir a um hospital. Seu pronto assentimento instala a passagem de um alheamento a um anelamento, ou seja, ao estabelecimento de um primeiro laço social, representado pelos técnicos da atenção. No lugar do anel que Ihe corta a carne, mas que, de alguma forma, Ihe dá consistência de corpo e "contorno do real na estrutura" (Schaustz, 2000), um anel com o Outro se faz. Esse acontecimento possibilitou sua permanência, durante 15 dias, no setor de cirurgia plástica em um hospital de urgência, situado na área central da cidade, onde recebeu os cuidados necessários a sua reabilitação.

A entrada de um andarilho maltrapilho e fétido em um hospital dessa natureza, acompanhado de uma equipe técnica, constitui-se em fato novo no campo da saúde pública em Belo Horizonte, e inaugurou uma série de negociações, cuidados e esclarecimentos que foram fatores fundamentais para a série de procedimentos que se seguiram: o contato com a equipe de plantão daquela unidade de urgência, a higienização do paciente, a discussão, com a equipe cirúrgica, sobre a pertinência ou não de se amputar o dedo anular do paciente, a procura de um serralheiro pelas dependências do hospital e imediações a partir da decisão pela retirada do anel, o que dispensou o recurso de uma amputação, e, finalmente, o suporte da equipe de enfermagem no acompanhamento após a cirurgia plástica que se realizou.

Após a alta programada junto ao setor de assistência social, ele é recebido em casa pelos familiares. Dois meses depois, volta para a rua, e seu quadro se agrava. Pedia-nos, quando nos aproximávamos, uma caixa de engraxate para trabalhar.Um novo telefonema da moradora da região nos informa que ele se encontrava transitando sem cessar, alheio entre os carros, 
forçando seu encaminhamento ao Cersam Leste, unidade de urgência em saúde mental do Município. O alto grau de insuportabilidade familiar exigiu dos técnicos envolvidos suportes de várias ordens, incluindo atendimentos aos irmãos e à mãe e esclarecimentos a ela com relação à verdadeira enfermidade do filho, sua relação com o tempo, com o outro, a necessidade da medicação continuada e a dificuldade com o trabalho, pelos menos nos moldes que ela esperava, inerente à sua condição mental.

Em um "atendimento feito por muitos" (Zenoni, 2000), primamos pela construção coletiva do caso, o que envolve ainda a palavra do paciente e de sua família. A mãe nos informa que, já há algum tempo, ele se envolve com afazeres da casa, de forma aceitável. O "Senhor dos Anéis" mantém-se fiel aos laços estabelecidos em sua trajetória de rua, com a proprietária de um restaurante, que lhe dá algum tipo de trabalho semanal, com a senhora que mora próximo ao seu antigo lugar de fixação e tem comparecido mensalmente à unidade de saúde de referência para psicoterapia e medicação de forma espontânea.

(Garcia, 2002) nos diz que "Lidar com alguém inapto à subjetivação seria sustentar, até o último instante, a possibilidade de que algo aconteça, ínfimo movimento que faça surgir um sujeito, a partir de uma ética que deve avaliar o que pode um sujeito e o que desse poder ele é capaz de fazer. O sujeito se faz cidadão quando o espaço público se desdobra e expande as particularidades subjetivas". A evolução desse ex-morador de rua nos reforça a hipótese segundo a qual, nesse tipo de intervenção, é possível contar com uma mobilização da subjetivação, o que permite apostar na possibilidade de rearranjos subjetivos, aliados aos novos modos de vida do sujeito. 
Maria Mercedes Merry Brito Psicóloga/psicanalista. Especialista em Filosofia/UFMG. Mestre em Ciências Sociais pela PUC/MG

Recebido 27/01/03 Reformulado 13/02/06 Aprovado 14/03/06

COULON, Alain. A Escola de Chicago.São Paulo: Papirus, 1992. CALVINO, Ítalo. As Cidades Invisíveis. São Paulo: Companhia das Letras, 1999.

CALVINO, Ítalo.Marcovaldo ou as Estações na Cidade. São Paulo: Companhia das Letras, 1997.

DIZEM que Sou Louco. Direção: Miriam Chnaiderman, Produção: Vídeo Track.Apoio: Secretaria do Estado da Cultura, São Paulo, 1992

FREUD, Sigmund. O Caso de Schereber. Artigos sobre Técnica e outros Trabalhos. Livro XII. Coleção Standard. Rio de Janeiro: Imago, 1911.

GARCIA,Célio. Psiquiatria, Psicologia e Saúde Mental. Belo Horizonte: Oficina de Arte e Prosa, 2002.

LEFEBVRE, Henri. A Revolução Urbana. Belo Horizonte: Humanitas, UFMG, 1999.
PESSANHA, Neves Delma. Perfil da População de Rua. In Rosa, Cleisa M.M. (org). População de Rua-Brasil e Canadá. São Paulo: Hucitec, 1995.

FOUCAULT, Michel. História da Loucura. São Paulo: Perspectiva, 1999.

SCHAUSTZ, André. Corpo e Psicose. Revista da Escola Letra Freudiana, ano XVII, ㄲo 27. Rio de Janeiro, 2000.

SOLER, Colette. Estúdios Sobre As Psicoses. Argentina: Manantial, 1993.

FERREIRA, Tânia. Os Meninos e a Rua.Uma Interpelação à Psicanálise. Belo Horizonte: Autêntica, 2001.

ZENONI, Alfredo. "A Clínica da Psicose: o Trabalho Feito por Muitos". Revista Abre Campos, ano I - no o. Belo Horizonte: Instituto Raul Soares, 2000. 